\title{
Synthesis and Characterization of Cerium Doped Titanium Catalyst for the Degradation of Nitrobenzene Using Visible Light
}

\author{
Padmini Ellappan and Lima Rose Miranda \\ Department of Chemical Engineering, A. C. Tech, Anna University, Chennai 600 025, India \\ Correspondence should be addressed to Lima Rose Miranda; limamiranda2007@gmail.com
}

Received 22 May 2013; Accepted 3 October 2013; Published 6 January 2014

Academic Editor: Manickavachagam Muruganandham

Copyright (C) 2014 P. Ellappan and L. R. Miranda. This is an open access article distributed under the Creative Commons Attribution License, which permits unrestricted use, distribution, and reproduction in any medium, provided the original work is properly cited.

\begin{abstract}
Cerium doped catalyst was synthesized using Titanium isopropoxide as the Titanium source. The metal doped nanoparticles semiconductor catalyst was prepared by sol-sol method with the sol of Cerium. The synthesized catalyst samples were characterized by powder X-ray diffraction, BET surface area, thermogravimetric analysis (TGA), scanning electron microscopy (SEM), and UV-vis diffuse reflectance measurements (DRS) and compared with undoped $\mathrm{TiO}_{2}$ catalyst. The photocatalytic activity of the sample was investigated for the decomposition of nitrobenzene (NB) using visible light as the artificial light source. Cerium doped catalyst was found to have better degradation of nitrobenzene owing to its shift in the band gap from UV to visible region as compared to undoped $\mathrm{TiO}_{2}$ catalyst. The operational parameters were optimized with catalyst dosage of $0.1 \mathrm{gL}^{-1}, \mathrm{pH}$ of 9 , and light intensity of $500 \mathrm{~W}$. The degradation mechanism followed the Langmuir Hinshelwood kinetic model with the rate constant depending nonlinearly on the operational parameters as given by the relationship $K_{\text {app }}$ (theoretical) $=2.29 * 10^{-4} *$ Intensity $^{0.584} *$ Concentration $^{-0.230} *$ Dosage $^{0.425} * \mathrm{pH}^{0.336}$.
\end{abstract}

\section{Introduction}

The mechanism of photocatalysis using a semiconductor is by charge carrier generation resulting in the formation of holes, charge carrier trapping to form hydroxyl radicals, and recombination of electrons and holes where heat is generated.

Heterogeneous photocatalytic systems based on $\mathrm{TiO}_{2}$ catalysts show some limitations that reduce their impact in the domain of environmental protection. Important limitations are low photonic yield and little efficiency under visible light. These limitations have recently been the source of great development in the area of the production and characterization of $\mathrm{TiO}_{2}$-based photocatalysts, capable of being efficiently used under visible irradiation or showing a higher photochemical yield in the near UV region.

Any semiconductor material could be activated using a light whose wavelength greatly depends on the band gap of the semiconductor catalyst. Apart from the band gap, there have been other properties like surface area, crystal composition, particle size distribution, and porosity which have an influential effect on the degradation of the compound. Band gap reduction could be done by dye sensitization, doping, bimetallic semiconductor, and surface modification. By reducing the band gap, use of visible light could be employed as an alternative to UV light which may result in better economics. Various nonmetal elements, such as B [1], C [2], N [3], V [4], and S [5], have been successfully doped into $\mathrm{TiO}_{2}$ nanomaterials. Surface area, crystal composition, and particle size distribution can be varied by varying the preparation methods like preparation using solgel method wherein uniform crystal structure with better properties could be achieved. Several researchers have modified $\mathrm{TiO}_{2}$ with transition metals. Deposition of noble metals $\mathrm{Ag}, \mathrm{Au}, \mathrm{Pt}$, and $\mathrm{Pd}[6,7]$ on the surface of $\mathrm{TiO}_{2}$ enhances the photocatalytic efficiency by acting as an electron trap, promoting interfacial charge transfer and therefore delaying recombination of the electron-hole pair. Another technique involves $\mathrm{TiO}_{2}$ doping with transition metals such as $\mathrm{Fe}, \mathrm{Cu}, \mathrm{Co}, \mathrm{Ni}, \mathrm{Cr}, \mathrm{V}, \mathrm{Mn}$, 
$\mathrm{Mo}, \mathrm{Nb}, \mathrm{W}, \mathrm{Ru}, \mathrm{Pt}$, and $\mathrm{Au}[8,9]$. The incorporation of transition metals in the titania crystal lattice may result in the formation of new energy levels between valence band and conduction band, inducing a shift of light absorption towards the visible light region. Photocatalytic activity depends on the nature and the amount of doping agent. Possible limitations are photocorrosion and promoted charge recombination at metal sites. Choi et al. [10] has made an extensive study by doping with $\mathrm{Fe}^{3+}, \mathrm{Mo}^{5+}, \mathrm{Ru}^{3+}, \mathrm{Os}^{3+}, \mathrm{Re}^{5+}, \mathrm{V}^{4+}$, and $\mathrm{Rh}^{3+}$ and concluded that there was an increase in the photoreactivity for both oxidation and reduction of the organic compound.

Cerium, among the lanthanides, has a band gap of $\sim 3 \mathrm{eV}$. Hence, it has strong absorption and shows better optical properties. Ce (III) and Ce (IV) have the high oxygen storage capacity which enhances the catalytic potential, also its oxidation ability of $\mathrm{Ce}^{3+}$ to $\mathrm{Ce}^{4+}$ states leads to high oxygen mobility resulting in better catalytic performance [11, 12]. It has also been demonstrated by many researchers that there are many advantages because of Cerium doping [13]. Chen et al. [14] and Liu et al. [15] have also established that there was a shift towards visible region due to doping of titania with Cerium.

Nitrobenzene, an aromatic compound used in the manufacture of aniline, has moderate to low water solubility. This nitroaromatic compound has been listed as a carcinogen by the National Institute of Environmental Health Sciences. The maximum permissible limit for Nitrobenzene in drinking water is $17 \mathrm{ppm}$ as recommended by the U.S. EPA. Nitrobenzene has been widely used as solvent and in manufacture of dye intermediates and pesticides. Due to its carcinogenic and mutagenic properties, it has to be eliminated from the water streams. Prolonged exposure causes damage to lung by irritation, anaemia, and liver damage. A number of workers illustrate the removal or degradation of this compound by different biological methods like bioaugmentation and oxidative reduction by bioremediation. Works has been carried out on the degradation of nitrobenzene using white root fungus and glow discharge plasma. Owing to the disadvantages of these procedures due to noneconomical degradation time and complicated equipment designs leading to increased cost, there has been extensive research in identifying techniques which would show better performance. One such technique found to be effective over the years is the use of advanced oxidation process, photocatalysis. Authors like Tayade et al. [6], Priya and Madras [7], and Bhatkhande et al. [16] have worked on the degradation of Nitrobenzene using semiconductor catalysts and an artificial light source.

The main objectives of the present research work are (i) synthesis and characterization of $\mathrm{TiO}_{2}$ doped with Cerium photocatalysts, (ii) photocatalytic degradation of Nitrobenzene pollutant in aqueous suspensions using the doped catalyst and undoped catalyst under visible light, (iii) optimization of operational parameters, and (iv) detailed kinetic study using Langmuir Hinshelwood model.

\section{Experimental Procedures}

2.1. Chemical Reagents and Apparatus. All chemicals used in this experiment were of analytical grade. Titanium isopropoxide, Titanium dioxide, Cerium oxide, ethanol, and glacial acetic acid are supplied by SRL chemicals, Mumbai, India. In all the experiments double distilled water was used.

2.2. Catalyst Characterization. X-ray diffraction (XRD) (Siemens D5000) was performed on fresh synthesized catalyst. The X-ray powder diffraction pattern of the powder sample was measured employing $\mathrm{CuK} \alpha$ radiation. The data were collected over diffraction angle of $5^{\circ}$ to $80^{\circ}$ in $2 \theta$ with a step scanning. The accelerating voltage and the applied current were $40 \mathrm{kV}$ and $40 \mathrm{~mA}$, respectively.

The surface chemical analysis of the samples was made by X-ray Photoelectron Spectroscopy (AXIS His; Kratos Analytical) using $\mathrm{MgK} \alpha$ X-ray source $(h v=1253.6 \mathrm{eV})$ and an analyzer pass energy of $40 \mathrm{eV}$. The physical adsorption of nitrogen was performed on a NOVA 1000 system (Quantachrome) at $77 \mathrm{~K}$. Surface areas of the samples were calculated based on the BET model.

The DRS spectra of all the samples were recorded to determine the sample's UV-VIS light absorption capacity, on a Jasco-V650 diode array, computer controlled (with SpectraManager software) spectrophotometer equipped with an $I L V-724$ integration sphere. The recorded spectral data was acquired in the $220-800 \mathrm{~nm}$ range, with $0.5 \mathrm{~nm}$ data pitch and $100 \mathrm{~nm} / \mathrm{min}$ scan speed. When higher resolution of the spectra was needed (usually in the $400-525 \mathrm{~nm}$ ) the data pitch was changed to $0.05 \mathrm{~nm}$ and the scan speed to $50 \mathrm{~nm} / \mathrm{min}$.

SEM-EDX analysis was performed to evaluate the morphology of the amorphous starting material and the obtained well crystallized catalysts on a Hitachi S-4700 Type II cold field emission scanning electron microscope equipped with a Röntec QX2-EDS spectrometer.

2.3. Photoreactor. The experiments were performed in an annular photoreactor with a separate immersion well for the visible lamp. The lamps were cooled using circulating water. The reactor was of $500 \mathrm{~mL}$ capacity. The samples were taken at known intervals of time and absorbance was measured using UV-spectrophotometer.

2.4. Preparation of Catalyst. Titanium dioxide was prepared by solgel method using Titanium isopropoxide as precursor. Titanium dioxide sol was prepared using Titanium isopropoxide as precursor. $8 \mathrm{~mL}$ of Titanium isopropoxide was mixed with $42 \mathrm{~mL}$ of ethanol and stirred well. To this $100 \mathrm{~mL}$ of $50 \%$ ethanol was added slowly and continuously stirred for $30 \mathrm{~min}$ at a temperature of $80^{\circ} \mathrm{C}$ for the hydrolysis reaction to take place, a method modified and adopted from Saif and Abdel-Mottaleb [17]. A modified method was adopted for Cerium sol preparation from Alouche [18]. $65 \mathrm{~g}$ of Cerium nitrate was dissolved in $1 \mathrm{~L}$ of glacial acetic acid. This solution was added to $1 \mathrm{~L}$ of $10 \%$ ammonia. This is the sol of Cerium. This sol was then added to $\mathrm{TiO}_{2}$ sol and stirred uniformly and continuously. It was then left for ageing for 24 hours and then calcined at $400^{\circ} \mathrm{C}$ for 4 hours. This catalyst is referred to as $\mathrm{TiO}_{2}$-Ce. 


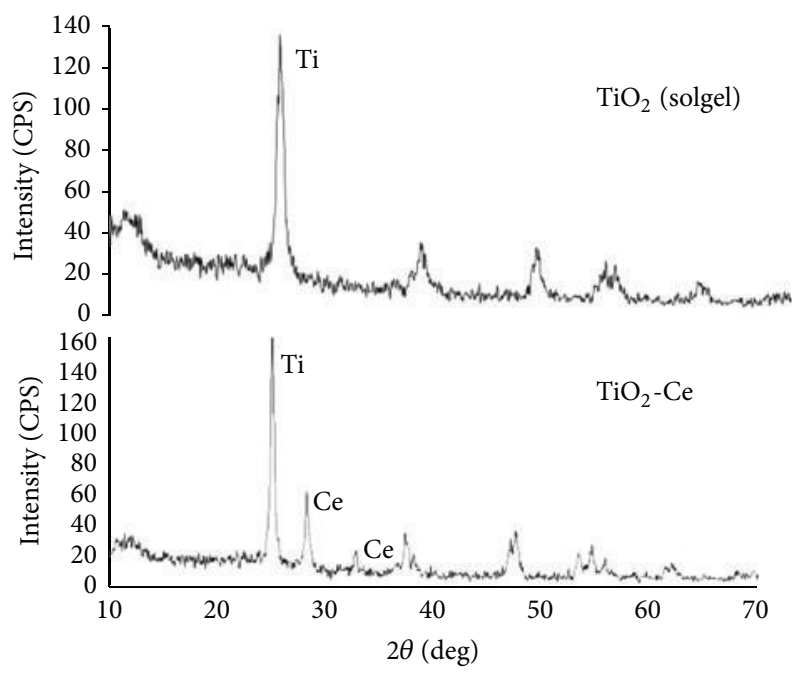

Figure 1: XRD analysis of $\mathrm{TiO}_{2}$ and $\mathrm{TiO}_{2}$-Ce.

2.5. Degradation Experiment. The batch degradation experiment was performed in an annular photoreactor by taking a known quantity of catalyst to aqueous solution of concentrations ranging between 25 and $200 \mathrm{mg} \mathrm{L}^{-1}$. Visible light of $150 \mathrm{~W}, 300 \mathrm{~W}$, and $500 \mathrm{~W}$ was used for degradation and the solution was irradiated for 7 hours. Samples were collected at different intervals of time and the solution was analysed for concentration of nitrobenzene by reading the absorbance at $264.5 \mathrm{~nm}$ in an UV spectrophotometer. The percentage degradation was the reduction in concentration compared to the original concentration as given in

$$
\text { Percentage degradation }=\frac{C_{0}-C}{C_{0}} * 100 \text {, }
$$

where $C_{0}$ is the initial concentration of the aqueous solution and $C$ is the concentration at any time $t$. The unknown concentration of the solution at any time can be predicted from the standard plot of absorbance and concentration of the solution.

\section{Results and Discussion}

3.1. Catalyst Characterization. XRD patterns were recorded for the prepared and calcined samples on a graphite crystal monochromator, operating with a $\mathrm{Cu}$ anode and a sealed $\mathrm{X}$-ray tube as shown in Figure 1 . For the range of $20-80^{\circ}$ with $0.05^{\circ}$ step size, the $2 \theta$ scans were recorded at several resolutions using $\mathrm{CuK}_{\alpha}$ radiation of wavelength $1.54 \AA$. Average particle size was determined by using full width at half maximum (FWHM) data. Scherer's formula (2) was used to determine average particle size as follows:

$$
D=\frac{k \lambda}{\beta \operatorname{Cos} \theta},
$$

where $D$ is the diameter of the particle, $k$ is a constant equal to $0.89, \lambda$ is the $\mathrm{X}$-ray wavelength equal to $0.154 \mathrm{~nm}, \beta$ is the full width at half maximum, and $\theta$ is the half diffraction angle [4]. The XRD pattern of solgel- $\mathrm{TiO}_{2}$ showed primary
TABLE 1: Physical characterization of the catalysts.

\begin{tabular}{lcccc}
\hline Catalyst & $\begin{array}{c}S_{\mathrm{BET}}, \\
\mathrm{m}^{2} \mathrm{~g}^{-1}\end{array}$ & $\begin{array}{c}\text { Pore volume, } \\
\mathrm{cm}^{3} \mathrm{~g}^{-1}\end{array}$ & $\begin{array}{c}\text { Paricle diameter, nm } \\
\text { Scherer's } \\
\text { formula }\end{array}$ & Using $S_{\mathrm{BET}}$ \\
\hline $\mathrm{TiO}_{2}$ (solgel) & 102 & 0.34 & 13.21 & 14.01 \\
$\mathrm{TiO}_{2}$-Ce & 92 & 0.20 & 19.14 & 20.04 \\
\hline
\end{tabular}

anatase peaks at $25.06^{\circ}, 47.54^{\circ}, 54.46^{\circ}$, and $61.72^{\circ}$. The rutile phase of solgel- $\mathrm{TiO}_{2}$ was indicated by the peaks $37.4^{\circ}$ and $53.63^{\circ}$. Titanium dioxide in the anatase form is generally accepted to be the most active polymorph [19]. This better efficiency is attributed to a higher degree of hydroxylation of anatase when compared with that of the rutile phase. The XRD patterns of Ce doped $\mathrm{TiO}_{2}$ samples almost coincide with those of pure solgel- $\mathrm{TiO}_{2}$ but show diffraction peaks due to cerium doping. The average particle sizes of solgel- $-\mathrm{TiO}_{2}$ and $\mathrm{TiO}_{2}$-Ce were calculated and tabulated in Table 1 .

The particle size was also calculated using surface area calculated from BET isotherms determined using BET Quantachrome instruments as given in (3). The surface area, average pore area, and particle size calculated are shown in Table 1. Consider the following:

$$
\text { Particle Diameter } D=\frac{6000}{S_{\mathrm{BET}}} \text {, }
$$

where $S_{\mathrm{BET}}$ is the surface area $\left(\mathrm{cm}^{2} \mathrm{~g}^{-1}\right)$ and $\rho$ is the density of the catalyst which is approximately $4.2 \mathrm{gc} \mathrm{m}^{-3}$ for titania based particles. The ionic radii of $\mathrm{Ce}^{3+}$ and $\mathrm{Ti}^{2+}$ are $0.101 \mathrm{~nm}$ and $0.068 \mathrm{~nm}$, respectively. $\mathrm{Ce}^{3+}$ could not be incorporated into the lattice of $\mathrm{TiO}_{2}$ and hence there was an increase in particle size. As the particle size increases, the surface area decreases as seen from Table 1.

The valence state of Cerium in the $\mathrm{TiO}_{2}$-Ce sample was examined by XPS. The XP spectrum in Figure 2 shows the characteristic Ce $3 \mathrm{~d}$ peak that has a binding energy of $887.3 \mathrm{eV}$; XPS peaks corresponding to $\mathrm{Ce}^{4+}$ ion were not found. This result confirms the presence of Cerium deposits on the $\mathrm{TiO}_{2}$ surface of the $\mathrm{TiO}_{2}$-Ce sample. The binding energies for $\mathrm{Ti} 2 \mathrm{p}$ were $458.3 \mathrm{eV}$ and $464.1 \mathrm{eV}$ as shown in Figure 2. Combined with the XRD analysis, it could be understood that the doping cerium atoms presented in the forms of $\mathrm{Ce}_{2} \mathrm{O}_{3}$ and were distributed on the surface of titania.

Figure 3 shows SEM photograph of the typical samples of $\mathrm{TiO}_{2}$ (a) and $\mathrm{TiO}_{2}-\mathrm{Ce}$ (b). From the image, the sample $\mathrm{TiO}_{2}$-Ce existed approximately in the form of spherical particle and presented porous structures similar to those of $\mathrm{TiO}_{2}$. According to the statistical estimation, the average size was about $14.5 \mathrm{~nm}$, which was in accordance with the value determined by XRD $(19.14 \mathrm{~nm})$. The morphological study shows that for both $\mathrm{TiO}_{2}$ and $\mathrm{TiO}_{2}$-Ce catalyst, the surface looked almost the same with slightly whitish portion indicating the deposition of Ce. On the basis of the SEM results, the Ti Ka-fluorescence signals for the pure $\mathrm{TiO}_{2}$ and $\mathrm{TiO}_{2}$-Ce samples were also obtained by EDX analysis and the spectra are shown in Figure 4, which gave both qualitative 


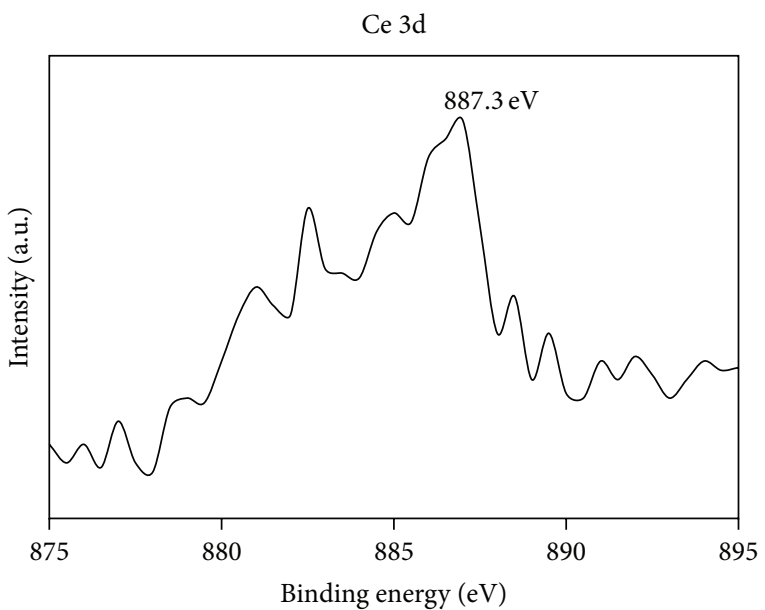

(a)

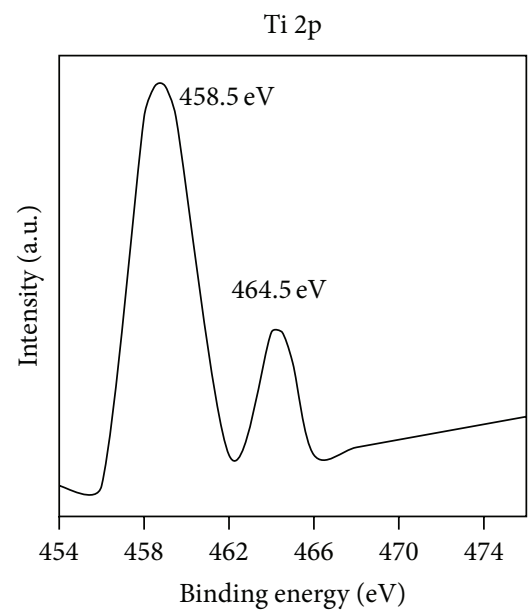

(b)

FIgURE 2: XPS analysis of $\mathrm{TiO}_{2}$-Ce doped catalyst.
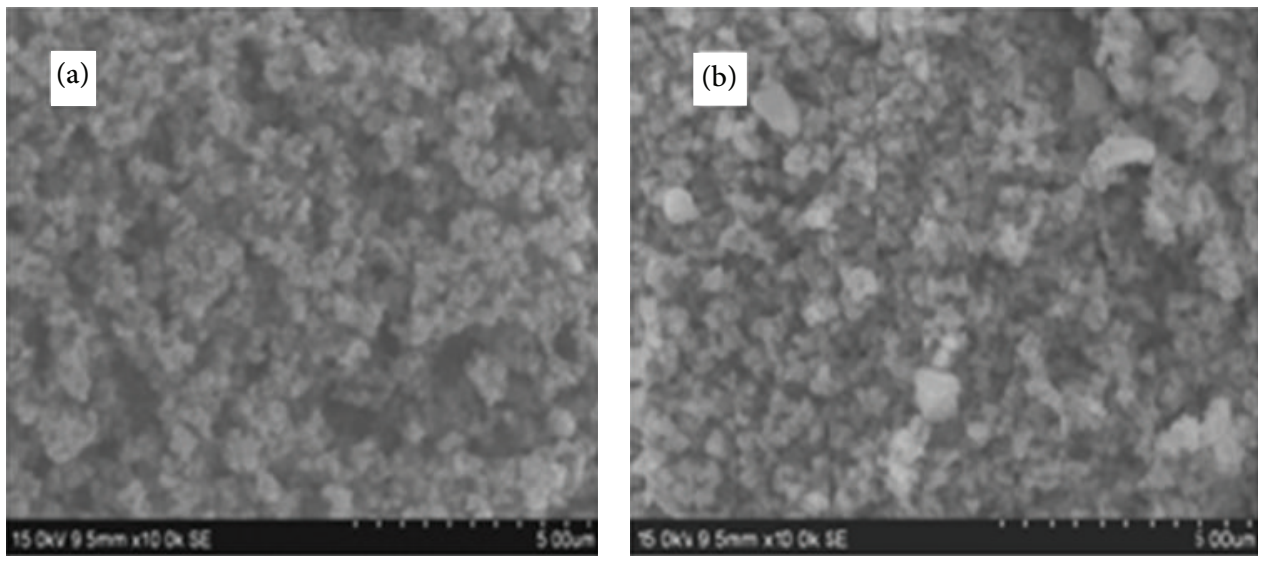

FIgure 3: SEM analysis of $\mathrm{TiO}_{2}$ (a) and $\mathrm{TiO}_{2}-\mathrm{Ce}$ (b) doped catalyst.

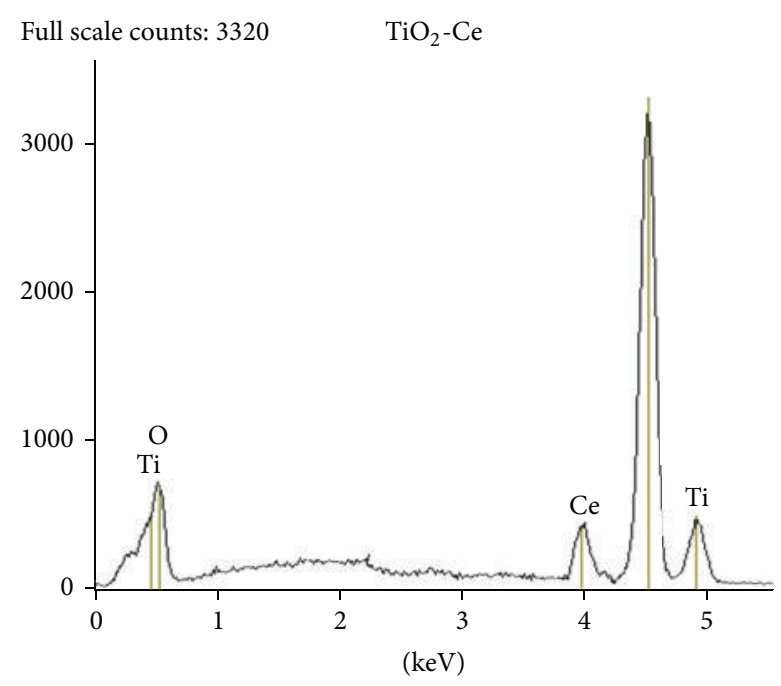

(a)

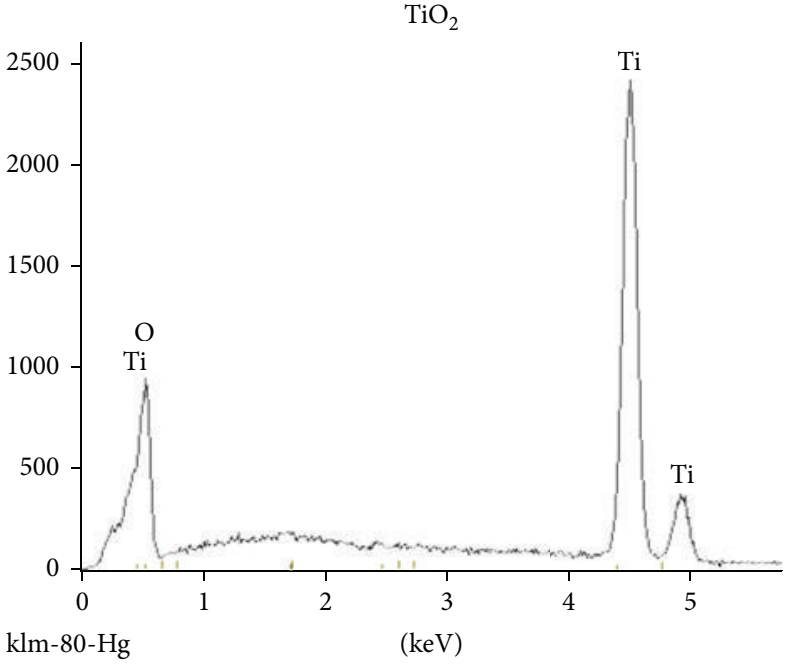

(b)

FIgURE 4: EDX analysis of $\mathrm{TiO}_{2}$-Ce doped and $\mathrm{TiO}_{2}$ catalyst. 
TABLE 2: Catalyst composition using EDX analysis of $\mathrm{TiO}_{2}$ and $\mathrm{TiO}_{2}$-Ce catalyst.

\begin{tabular}{lcc}
\hline \multirow{2}{*}{ Element } & \multicolumn{2}{c}{ Compound \% } \\
& $\mathrm{TiO}_{2}$ & $\mathrm{TiO}_{2}-\mathrm{Ce}$ \\
\hline $\mathrm{O}$ & 11.83 & 19.65 \\
$\mathrm{Ti}$ & 88.17 & 76.56 \\
$\mathrm{Ce}$ & - & 3.79 \\
\hline
\end{tabular}

and quantitative information about the elemental and atomic percentages in the $\mathrm{TiO}_{2}$ and $\mathrm{TiO}_{2}$-Ce samples, as presented in Table 2.

In order to estimate the band gap distance, UV-vis spectroscopy was employed. An Oriel Instruments spectrometer with an integrating sphere was used for UV-Vis spectrometry measurements to analyze the red-shifts in the absorption regions. The UV-Vis transmittance measurements were taken and converted into absorption readings as given in Figure 5. For pure $\mathrm{TiO}_{2}$, the band gap energy correpsonding to $388.8 \mathrm{~nm}$ indicates $3.18 \mathrm{eV}$ which was found to be in accordance with that of other researchers [20-22], while for $\mathrm{TiO}_{2}-\mathrm{Ce}$, the band gap energy reduced due to the shift of absorbance further away from UV region. The band gap energy corresponding to the wavelength of $551.4 \mathrm{~nm}$ was determined to be $2.25 \mathrm{eV}$. The results show that cerium does improve visible light absorbance of $\mathrm{TiO}_{2}$ due to cerium plasmon absorption.

3.2. Control Experiment. Photocatalytic degradation studies were performed using $\mathrm{TiO}_{2}$-Ce and compared with undoped $\mathrm{TiO}_{2}$. The catalyst dosage was uniformly taken to be $0.1 \mathrm{~g} \mathrm{~L}^{-1}$ for all the experiments with solution concentration to be $50 \mathrm{mg} \mathrm{L}^{-1}, \mathrm{pH}$ of 6.8 , and different light intensities $(150,300$, and $500 \mathrm{~W}$ ). From Figure 6, it could be seen that using $\mathrm{TiO}_{2}-$ Ce and $500 \mathrm{~W}$ light, the degradation achieved was $79.09 \%$ which was higher than the other catalysts studied. Addition of Cerium to $\mathrm{TiO}_{2}$ has increased the percentage of degradation by $14 \%$ when compared to $\mathrm{TiO}_{2}$. The photolytic degradation of nitrobenzene was performed in the absence of the catalyst varying the intensity of the visible light for comparing the performance of cerium doped catalyst as shown in Figure 6. The degradation using 150, 300, and $500 \mathrm{~W}$ was found to be 23,25 , and $29 \%$, respectively. This was much lower than the degradation using Cerium doped catalyst.

Though the particle size of $\mathrm{TiO}_{2}-\mathrm{Ce}$ was higher than $\mathrm{TiO}_{2}$ (solgel), it showed better degradation because, in photocatalysis, doping a semiconductor changed the photocatalytic process by suppressing electron-hole recombination and when the electron formed due to excitation migrates to the metal, it gets trapped within. The organic compound diffuses to the free hole on the semiconductor surface and oxidation of nitrobenzene occurs. The presence of cerium species on $\mathrm{TiO}_{2}$ influences the photoreactivity by altering the electronhole pair recombination rate through the following equations (4)-(7). The reduction in band gap energy from $3.2 \mathrm{eV}$ to

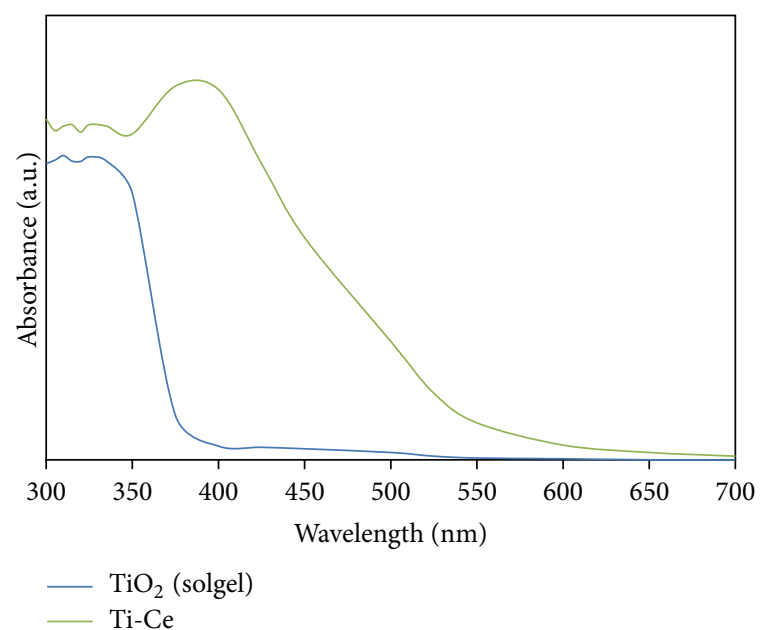

FIgURE 5: UV-DRIFT analysis of $\mathrm{TiO}_{2}$ and $\mathrm{TiO}_{2}$-Ce catalyst.

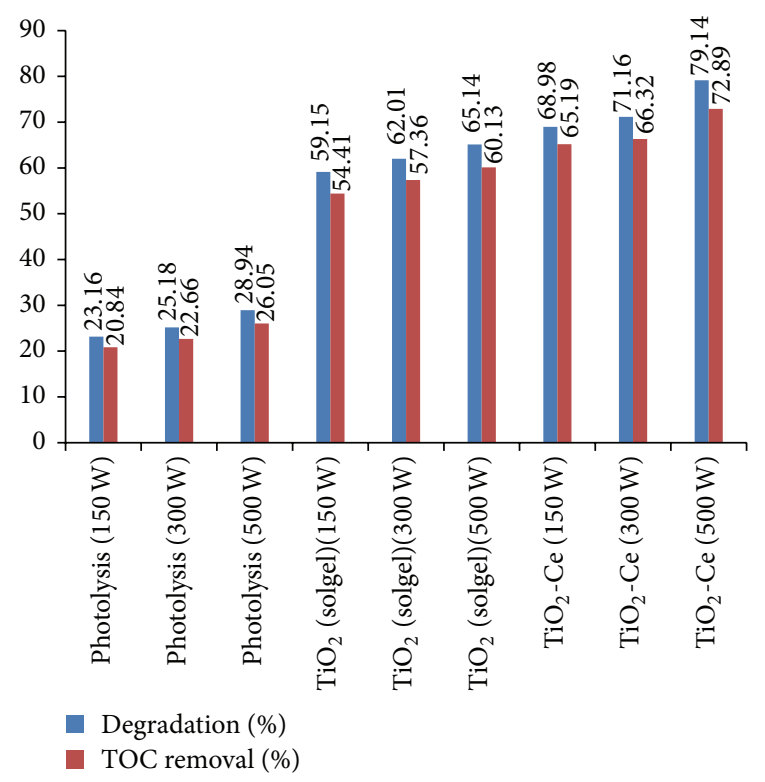

FIgURE 6: Degradation \% of NB for different catalysts at different intensities (Conc.: $50 \mathrm{mg} \mathrm{L}^{-1}$, $\mathrm{pH}$ : 6.8, and catalyst dosage: $0.1 \mathrm{~g} \mathrm{~L}^{-1}$ ).

$2.25 \mathrm{eV}$ also contributed to this increase in degradation. Consider

$$
\begin{gathered}
\mathrm{Ce}^{3+}+\mathrm{O}_{2} \longrightarrow \mathrm{O}^{-2}+\mathrm{Ce}^{4+} \\
\mathrm{Ce}^{4+}+\mathrm{e}^{-} \longrightarrow \mathrm{Ce}^{3+} \\
\mathrm{Ce}^{3+}+\mathrm{TiO}_{2}+h v \longrightarrow \mathrm{e}^{-}+\mathrm{h}^{+} \\
\mathrm{Ce}_{2} \mathrm{O}_{3}+h v \longrightarrow \mathrm{e}^{-}+\mathrm{h}^{+}
\end{gathered}
$$

The present study revealed that the cerium doped $\mathrm{TiO}_{2}$ in sol-sol method could be effectively used as compared to other catalysts as discussed in Table 3. Better shift of the catalyst towards visible region has resulted in $100 \%$ degradation at a $\mathrm{pH}$ of 9 and catalyst dosage of $0.1 \mathrm{gL}^{-1}$ (as summarized in Section 3.3.5). 
TABLE 3: Comparison of the performance of the present work with other published works.

\begin{tabular}{|c|c|c|c|c|}
\hline Catalyst & Properties & Light source & $\%$ degradation & Reference \\
\hline Ce doped $\mathrm{TiO}_{2}$ & $\begin{array}{l}\text { Particle size: } 10.8 \mathrm{~nm} \\
\text { Surface area: } 89.6 \mathrm{~m}^{2} \mathrm{~g}^{-1} \\
\text { Band gap: } 368 \mathrm{~nm}\end{array}$ & Visible & $\begin{array}{l}5 \% \text { for } 50 \mathrm{mgL}^{-1} \text { of } \\
\mathrm{NB} \text { solution }\end{array}$ & $\begin{array}{c}\text { Alouche (2008) } \\
{[18]}\end{array}$ \\
\hline $\mathrm{H}_{3} \mathrm{PW}_{12} \mathrm{O}_{40}-\mathrm{TiO}_{2}$ & & Visible & $\begin{array}{l}94.1 \% \text { of } 20 \mathrm{mgL}^{-1} \text { of } \\
\text { NB solution in } 6.5 \mathrm{hrs}\end{array}$ & $\begin{array}{l}\text { Tayade et al. } \\
\text { (2007) [19] }\end{array}$ \\
\hline Fe-ETS-10 & $\begin{array}{l}\text { Surface area: } 191 \mathrm{~m}^{2} \mathrm{~g}^{-1} \\
\text { Band gap: } 3.13 \mathrm{eV}\end{array}$ & UV & $\begin{array}{l}43 \% \text { of } 50 \mathrm{mgL}^{-1} \text { of } \\
\mathrm{NB} \text { solution in } 4 \mathrm{hrs}\end{array}$ & $\begin{array}{l}\text { Shen et al. } \\
(2009) \text { [20] }\end{array}$ \\
\hline $\begin{array}{l}\text { Nanocrystalline } \\
\mathrm{TiO}_{2}\end{array}$ & $\begin{array}{l}\text { Particle size: } 12 \mathrm{~nm} \\
\text { Surface area: } 166 \mathrm{~m}^{2} \mathrm{~g}^{-1} \\
\text { Band gap: } 3.28 \mathrm{eV}\end{array}$ & Visible & $\begin{array}{l}96 \% \text { of } 50 \mathrm{mgL}^{-1} \text { of } \\
\text { NB solution in } 8 \mathrm{hrs}\end{array}$ & $\begin{array}{l}\text { Tayade et al. } \\
\text { (2006) [6] }\end{array}$ \\
\hline $\begin{array}{l}\text { Silver metal } \\
\text { exchanged ETS-10 } \\
\text { Zeolite }\end{array}$ & $\begin{array}{c}\text { Surface area: } 205 \mathrm{~m}^{2} \mathrm{~g}^{-1} \\
\text { Band gap: } 3.16 \mathrm{eV}\end{array}$ & UV light $(267 \mathrm{~nm})$ & $\begin{array}{l}57 \% 50 \mathrm{mgL}^{-1} \text { of NB} \\
\text { solution in } 4 \mathrm{hrs}\end{array}$ & $\begin{array}{l}\text { Shen et al. } \\
(2009)[20]\end{array}$ \\
\hline N-Ce doped $\mathrm{TiO}_{2}$ & $\begin{array}{l}\text { Particle size: } 10.8 \mathrm{~nm} \\
\text { Surface area: } 152 \mathrm{~m}^{2} \mathrm{~g}^{-1} \\
\text { Band gap: } 2.19 \mathrm{eV}\end{array}$ & Visible (300 W xenon lamp) & $\begin{array}{l}53 \% 50 \mathrm{mgL}^{-1} \text { of NB} \\
\text { solution in } 4 \mathrm{hrs}\end{array}$ & $\begin{array}{c}\text { Alouche (2008) } \\
{[18]}\end{array}$ \\
\hline
\end{tabular}

The TOC removal \% was studied for different intervals of time. The photomineralization of the compounds were measured using Total Organic Carbon analyzer (Shimadzu TOC $5000 \mathrm{~A}$ ). The extent of TOC removal \% was compared with the undoped and Cerium doped $\mathrm{TiO}_{2}$ catalyst. The TOC removal \% was maximum using Cerium doped catalyst at an intensity of $500 \mathrm{~W}$.

\subsection{Optimization of Operational Parameters}

3.3.1. Effect of Solution Concentration. The most important operational parameter to be studied is the influence of initial concentration of the solution. NB photocatalytic degradation studies were carried out using 25-200 $\mathrm{mg} \mathrm{L}^{-1}$ initial concentration of $\mathrm{NB}$ and $0.1 \mathrm{~g} \mathrm{~L}^{-1}$ of catalyst loading. The plot of degradation \% for different solution concentration was made and from Figure 7 it could be inferred that as concentration increased, percentage degradation decreased. This may be due to the fact that with the increase in initial concentration of $\mathrm{NB}$, while the irradiation period and catalyst dose are kept constant, more NB molecules are present on the surface of $\mathrm{TiO}_{2}$. Thus, an increase in the number of substrate ions accommodating in interlayer spacing inhibits the action of the catalyst, which thereby decreases the number of reactive - $\mathrm{OH}$ and $\mathrm{O}_{2}^{--}$free radicals attacking the NB molecules, and, hence, lowers the photodegradation efficiency [23].

3.3.2. Effect of Light Intensity. The influence of light intensity on the degradation efficiency has been examined at constant Nitrobenzene concentration $\left(50 \mathrm{mg} \mathrm{L}^{-1}\right)$, at $\mathrm{pH}$ (6.5) and catalyst loading $\left(0.1 \mathrm{~g} \mathrm{~L}^{-1}\right)$. It is evident that the degradation rate increases with increase in the light intensity as shown in Figure 6. The photons required for the electron transfer were generated by UV irradiation which results in electron transfer from valence band to conduction band of the catalyst. The degradation \% increases when more radiations fall on

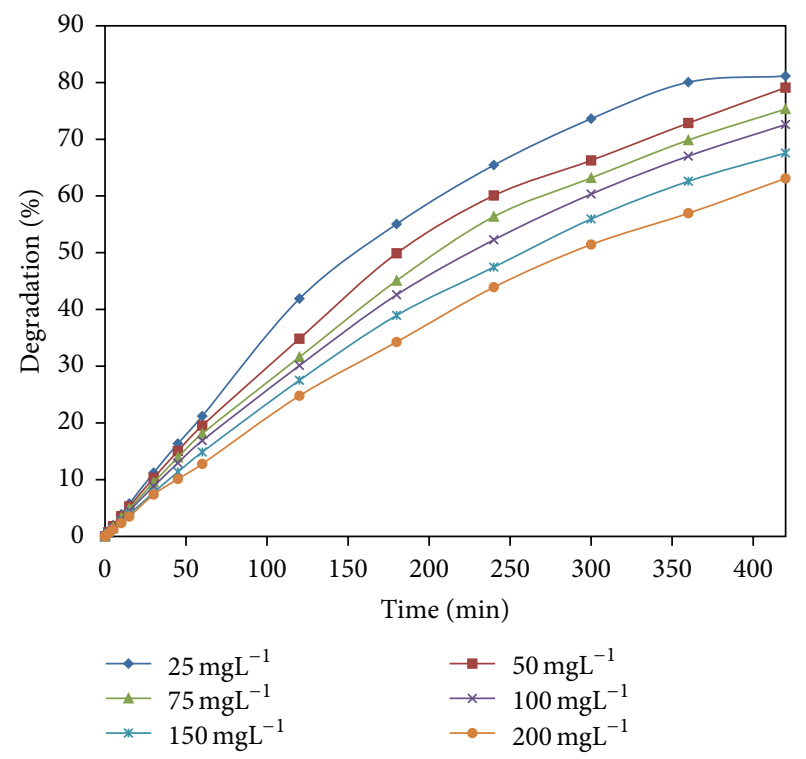

FIGURE 7: Effect of solution concentration on degradation \% (light intensity: $500 \mathrm{~W}, \mathrm{pH}: 6.8$, and catalyst dosage: $0.1 \mathrm{~g} \mathrm{~L}^{-1}$ ).

the catalyst surface and hence more hydroxyl radicals are produced [24].

3.3.3. Effect of Catalyst Dosage. Photocatalyst dosage added to the reaction vessel is a major parameter affecting the photocatalytic degradation efficiency. The aqueous solution of $50 \mathrm{mg} \mathrm{L}^{-1}$ of solution was degraded using different catalyst dosages $\left(0.025,0.05,0.1,0.15\right.$, and $\left.0.2 \mathrm{~g} \mathrm{~L}^{-1}\right)$. From Figure 8 it can be seen that maximum degradation was achieved for the catalyst dosage of $0.1 \mathrm{~g} \mathrm{~L}^{-1}$. It could also be inferred that further increase in catalyst dosage did not yield an increase in degradation percentage. 


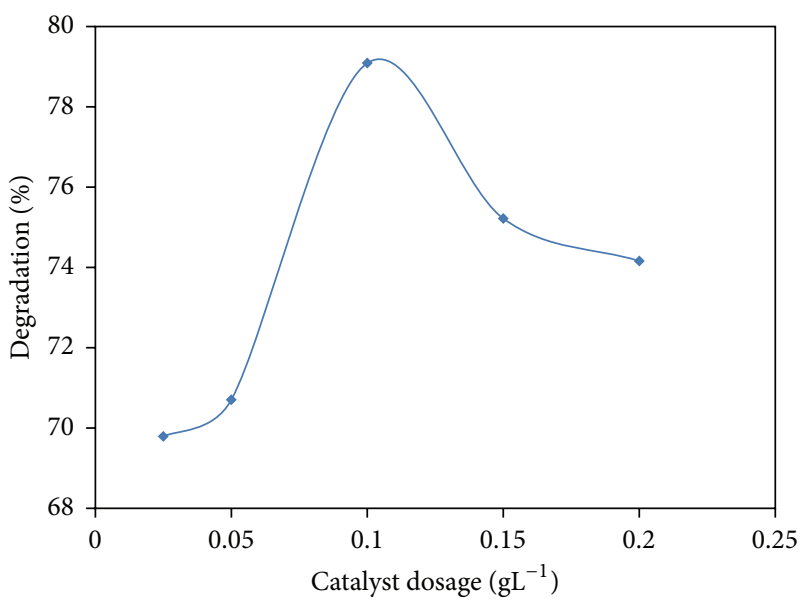

FIGURE 8: Effect of catalyst dosage on degradation \% (Conc.: $50 \mathrm{mg} \mathrm{L}^{-1}, \mathrm{pH}: 6.8$, and intensity: $500 \mathrm{~W}$ ).

The increase in degradation percentage for 0.025 to $0.1 \mathrm{~g} \mathrm{~L}^{-1}$ may be due to an increase in the amount of active sites on the surface of the photocatalyst particles. The number of NB molecules adsorbed as well as the number of photons absorbed increase with the increase in catalyst concentration thereby enhancing the rate of degradation. Addition of catalyst beyond $0.1 \mathrm{~g} \mathrm{~L}^{-1}$ leads to decrease in the degradation. Aggregation of $\mathrm{TiO}_{2}$ particles occurs at higher dosage causing decrease in the number of surface active sites and also there is an increase in the opacity of the solution and light scattering of $\mathrm{TiO}_{2}$ particles at high dosage through the solution [25].

3.3.4. Effect of $\mathrm{pH}$ of the Solution. $\mathrm{pH}$ of the solution greatly influences the degradation rate. It tends to change the surface property of the catalyst. The effect of change in initial $\mathrm{pH}$ $\left(2,4,6.5,8,9,10\right.$, and 11) of $50 \mathrm{mg} \mathrm{L}^{-1}$ of the nitrobenzene solution was studied by adding $0.1 \mathrm{~g} \mathrm{~L}^{-1}$ of catalyst. The plot of $\%$ degradation against $\mathrm{pH}$ (Figure 9) showed that as $\mathrm{pH}$ increased the degradation increased. A maximum of $100 \%$ degradation was achieved at $\mathrm{pH}$ 9. The degradation was lower in lower acidic and higher alkaline $\mathrm{pH}$.

$\mathrm{pH}$ of the catalyst dispersions majorly affects the surface properties on the particles, agglomerate size formed, and the conductance and valence bands positions [26]. The nitrobenzene solution was degraded by hydroxyl attack and direct oxidation at the holes and reduction at the conduction band. In alkaline $\mathrm{pH}$, the surface of $\mathrm{TiO}_{2}$-Ce acquires a negative charge leading to greater adsorption and hence increasing the degradation rate in the alkaline media.

\subsubsection{Kinetic Modelling Using Langmuir Hinshelwood Model.} The degradation percentage was calculated and for heterogeneous catalyst, the Langmuir Hinshelwood model was used to calculate the apparent rate constant. The Langmuir Hinshelwood model, derived based on the monolayer activity assumption, was used to estimate the kinetic parameters in

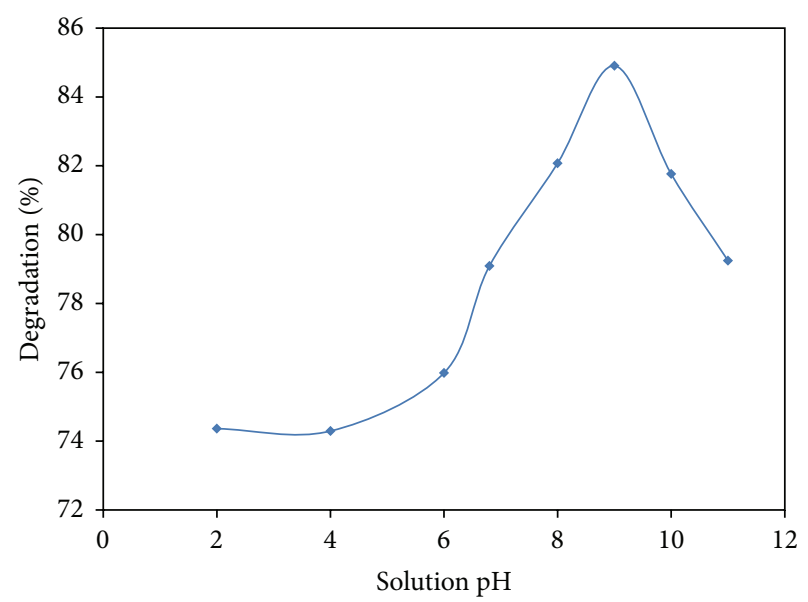

FIGURE 9: Effect of solution $\mathrm{pH}$ on degradation \% (Conc.: $50 \mathrm{mg} \mathrm{L}^{-1}$, catalyst dosage: $0.1 \mathrm{~g} \mathrm{~L}^{-1}$, and intensity: $\left.500 \mathrm{~W}\right)$.

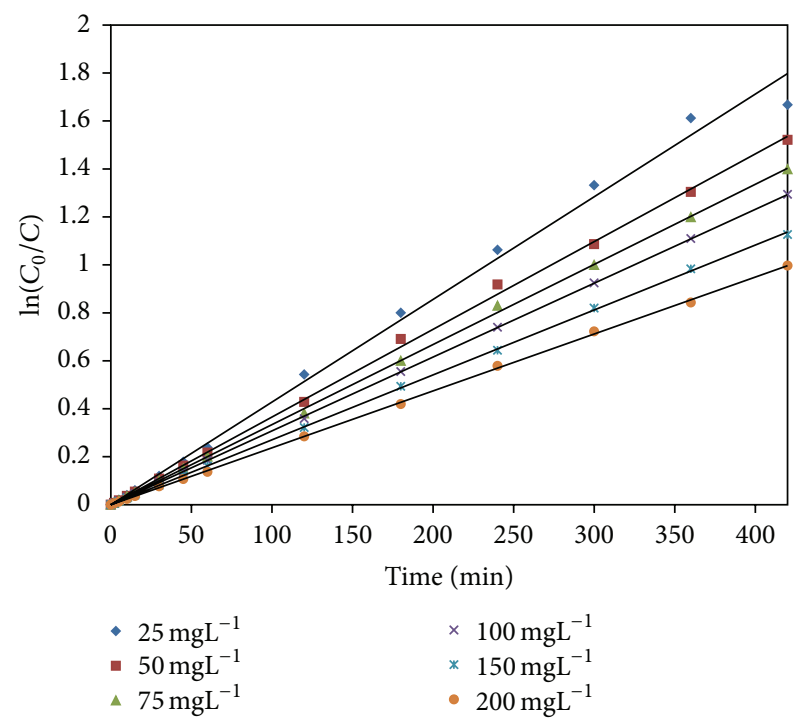

FIGURE 10: Langmuir Hinshelwood plot (pH: 6.8, catalyst dosage: $0.1 \mathrm{~g} \mathrm{~L}^{-1}$, and light intensity: $500 \mathrm{~W}$ ).

terms of reaction rate constant $\left(k_{r}\right)$ and Langmuir Hinshelwood adsorption constant $\left(K_{\mathrm{LH}}\right)$ which is as given in

$$
r=\frac{k_{r} K_{\mathrm{LH}} C}{1+K_{\mathrm{LH}} C_{0}}=k_{\mathrm{app}} C
$$

where is rate of disappearance of organic substrate, $\mathrm{mg} \mathrm{L}^{-1} \mathrm{~min}^{-1}$, and $C$ is concentration of organic substrate, $\mathrm{mg} \mathrm{L} \mathrm{L}^{-1}$,

$$
k_{\text {app }}=\frac{k_{r} K_{\mathrm{LH}}}{1+K_{\mathrm{LH}} C_{0}} .
$$

Linearization of (8) yields an equation from which a plot of $\ln \left(C_{0} / C\right)$ against time will result in a linear relationship resulting in zero intercept and apparent rate constant $\left(k_{\text {app }}\right)$ derived from the slope of the line. Figure 10 is the 


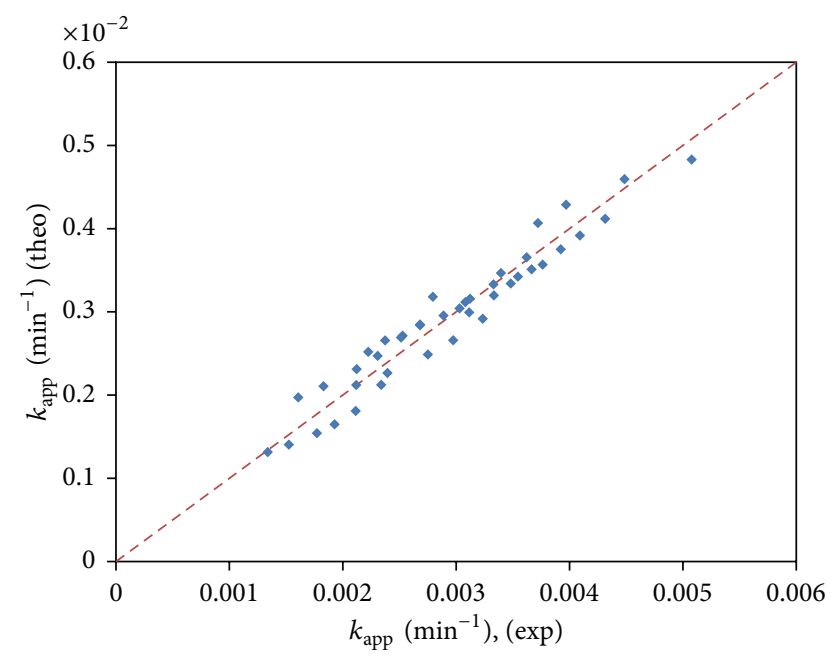

FIGURE 11: Comparison between the experimental and theoretical values of apparent rate constant.

representation of the plot from which the apparent rate constant was determined using slope of the line. Similarly for all the conditions of $\mathrm{pH}$ (2-11), concentration (25$\left.200 \mathrm{mg} \mathrm{L}^{-1}\right)$, catalyst dosage $\left(0.025-0.2 \mathrm{~g} \mathrm{~L}^{-1}\right)$, and intensity of visible light $(150-500 \mathrm{~W})$, the plot of $\ln \left(C_{0} / C\right)$ against time was evaluated. The apparent rate constant was found to increase with light intensity and decrease with solution concentration. The maximum degradation could be achieved at the following parameter condition: $\mathrm{pH}: 9$, dosage: $0.1 \mathrm{~g} \mathrm{~L}^{-1}$, solution concentration: $25 \mathrm{mg} \mathrm{L}^{-1}$, and light intensity: $500 \mathrm{~W}$. The nonlinear fit between the apparent rate constant and the operational parameters was determined and were found that the experimental values when compared with the theoretical values as in Figure 11, the theoretical values had less than 3\% error and hence the following equation (10) could be chosen for approximating the experimental conditions. Equation (10) could be used for a condition of $\mathrm{pH} 2$ to 9, dosage of 0.05 to $0.1 \mathrm{~g} \mathrm{~L}^{-1}$, light intensity of 150,300 , or $500 \mathrm{~W}$, and concentration of solution from 25 to $200 \mathrm{mg} \mathrm{L}^{-1}$. The nonlinear equation was

$$
\begin{aligned}
k_{\text {app }} & \text { (theoretical) } \\
= & 0.000229 * \text { Intensity }^{0.584} * \text { Concentration }^{-0.230} \\
& * \text { Dosage }^{0.425} * \mathrm{pH}^{0.336} .
\end{aligned}
$$

\section{Conclusion}

The undoped and cerium doped titania photocatalyst was prepared through the sol-gel route. The cerium doped photocatalyst could absorb the visible light and showed high photoactivity in the visible region because of the band gap narrowing. Cerium atoms existed in the state of $\mathrm{Ce}_{2} \mathrm{O}_{3}$ and were dispersed on the surface of titania, suppressing the recombination of electron-hole pairs and increasing the photoactivity as confirmed using XPS and DRIFT analysis.
The average crystal size and the surface area were determined and compared between two types of catalysts. The operational parameters were optimized and the following condition was suggested to obtain maximum degradation: pH: 9, dosage: $0.1 \mathrm{gL}^{-1}$, solution concentration: $25 \mathrm{mg} \mathrm{L}^{-1}$, and light intensity: $500 \mathrm{~W}$. The kinetic study revealed that the degradation followed Langmuir Hinshelwood model. The apparent rate constant was determined and evaluated theoretically using the nonlinear fit which depends on the operational parameters. Based on the previously mentioned experiments and characterization it could be concluded that Cerium doped $\mathrm{TiO}_{2}$ catalyst prepared by solgel method could be efficiently used for degradation of Nitrobenzene using visible light.

\section{Conflict of Interests}

The authors declare that there is no conflict of interests regarding the publication of this paper.

\section{References}

[1] S. C. Moon, H. Mametsuka, S. Tabata, and E. Suzuki, "Photocatalytic production of hydrogen from water using $\mathrm{TiO}_{2}$ and B/TiO 2 ," Catalysis Today, vol. 58, no. 2, pp. 125-132, 2000.

[2] C. Lettmann, K. Hildenbrand, H. Kisch, W. Macyk, and W. F. Maier, "Visible light photodegradation of 4-chlorophenol with a coke-containing titanium dioxide photocatalyst," Applied Catalysis B, vol. 32, no. 4, pp. 215-227, 2001.

[3] R. Asahi, T. Morikawa, T. Ohwaki, K. Aoki, and Y. Taga, "Visible-light photocatalysis in nitrogen-doped titanium oxides," Science, vol. 293, no. 5528, pp. 269-271, 2001.

[4] C.-S. Wu and C. Chen, "A visible-light response vanadiumdoped titania nanocatalyst by sol-gel method," Journal of Photochemistry and Photobiology A, vol. 163, no. 3, pp. 509-515, 2004.

[5] T. Umebayashi, T. Yamaki, S. Tanaka, and K. Asai, "Visible light-induced degradation of methylene blue on S-doped $\mathrm{TiO}_{2}$," Chemistry Letters, vol. 32, no. 4, pp. 330-331, 2003.

[6] R. J. Tayade, R. G. Kulkarni, and R. V. Jasra, "Photocatalytic degradation of aqueous nitrobenzene by nanocrystalline $\mathrm{TiO}_{2}$," Industrial and Engineering Chemistry Research, vol. 45, no. 3, pp. 922-927, 2006.

[7] M. H. Priya and G. Madras, "Photocatalytic degradation of nitrobenzenes with combustion synthesized nano- $\mathrm{TiO}_{2}$," Journal of Photochemistry and Photobiology A, vol. 178, no. 1, pp. 1-7, 2006.

[8] S. Ikeda, N. Sugiyama, B. Pal et al., "Photocatalytic activity of transition-metal-loaded titanium(IV) oxide powders suspended in aqueous solutions: correlation with electron-hole recombination kinetics," Physical Chemistry Chemical Physics, vol. 3, no. 2, pp. 267-273, 2001.

[9] A. Fuerte, M. D. Hernández-Alonso, A. J. Maira et al., "Visible light-activated nanosized doped- $\mathrm{TiO}_{2}$ photocatalysts," Chemical Communications, no. 24, pp. 2718-2719, 2001.

[10] W. Choi, A. Termin, and M. R. Hoffmann, "The role of metal ion dopants in quantum-sized $\mathrm{TiO}_{2}$ : correlation between photoreactivity and charge carrier recombination dynamics," Journal of Physical Chemistry, vol. 98, no. 51, pp. 13669-13679, 1994. 
[11] B. M. Reddy, P. M. Sreekanth, Y. Yamada, Q. Xu, and T. Kobayashi, "Surface characterization of sulfate, molybdate, and tungstate promoted $\mathrm{TiO}_{2}-\mathrm{ZrO}_{2}$ solid acid catalysts by XPS and other techniques," Applied Catalysis A, vol. 228, no. 1-2, pp. 269278, 2002.

[12] V. M. Orera, R. I. Merino, and F. Peña, "Ce3+↔Ce4+ conversion in ceria-doped zirconia single crystals induced by oxidoreduction treatments," Solid State Ionics, vol. 72, no. 2, pp. 224231, 1994.

[13] W. M. Yen, M. Raukas, S. A. Basun, W. Van Schaik, and U. Happek, "Optical and photoconductive properties of ceriumdoped crystalline solids," Journal of Luminescence, vol. 69, no. 5-6, pp. 287-294, 1996.

[14] S. W. Chen, J. M. Lee, K. T. Lu et al., "Band-gap narrowing of $\mathrm{TiO}_{2}$ doped with Ce probed with x-ray absorption spectroscopy," Applied Physics Letters, vol. 97, no. 1, Article ID 012104, 2010.

[15] H. Liu, X. Z. Li, Y. J. Leng, and W. Z. Li, "An alternative approach to ascertain the rate-determining steps of $\mathrm{TiO}_{2}$ photoelectrocatalytic reaction by electrochemical impedance spectroscopy," Journal of Physical Chemistry B, vol. 107, no. 34, pp. 8988-8996, 2003.

[16] D. S. Bhatkhande, V. G. Pangarkar, and A. A. C. M. Beenackers, "Photocatalytic degradation of nitrobenzene using titanium dioxide and concentrated solar radiation: chemical effects and scaleup," Water Research, vol. 37, no. 6, pp. 1223-1230, 2003.

[17] M. Saif and M. S. A. Abdel-Mottaleb, "Titanium dioxide nanomaterial doped with trivalent lanthanide ions of $\mathrm{Tb}, \mathrm{Eu}$ and Sm: preparation, characterization and potential applications," Inorganica Chimica Acta, vol. 360, no. 9, pp. 2863-2874, 2007.

[18] A. Alouche, "Preparation and characterization of Copper and/ or Cerium catalysts supported on Alumina or Ceria," Jordan Journal of Mechanical and Industrial Engineering, vol. 2, pp. 111116, 2008.

[19] R. J. Tayade, P. K. Surolia, R. G. Kulkarni, and R. V. Jasra, "Photocatalytic degradation of dyes and organic contaminants in water using nanocrystalline anatase and rutile $\mathrm{TiO}_{2}$," Science and Technology of Advanced Materials, vol. 8, no. 6, pp. 455-462, 2007.

[20] X.-Z. Shen, Z.-C. Liu, S.-M. Xie, and J. Guo, "Degradation of nitrobenzene using titania photocatalyst co-doped with nitrogen and cerium under visible light illumination," Journal of Hazardous Materials, vol. 162, no. 2-3, pp. 1193-1198, 2009.

[21] W. Wang, Y. Huang, and S. Yang, "Photocatalytic degradation of nitrobenzene wastewater with $\mathrm{H}_{3} \mathrm{PW}_{12} \mathrm{O}_{40} / \mathrm{TiO}_{2}$," in Proceedings of the International Conference on Mechanic Automation and Control Engineering (MACE '10), pp. 1303-1305, June 2010.

[22] P. K. Surolia, R. J. Tayade, and R. V. Jasra, "Photocatalytic degradation of nitrobenzene in an aqueous system by transitionmetal-exchanged ETS-10 zeolites," Industrial and Engineering Chemistry Research, vol. 49, no. 8, pp. 3961-3966, 2010.

[23] W. Bahnemann, M. Muneer, and M. M. Haque, "Titanium dioxide-mediated photocatalysed degradation of few selected organic pollutants in aqueous suspensions," Catalysis Today, vol. 124, no. 3-4, pp. 133-148, 2007.

[24] A. E. Cassano and O. M. Alfano, "Reaction engineering of suspended solid heterogeneous photocatalytic reactors," Catalysis Today, vol. 58, no. 2, pp. 167-197, 2000.

[25] A. A. Adesina, "Industrial exploitation of photocatalysis: progress, perspectives and prospects," Catalysis Surveys from Asia, vol. 8, no. 4, pp. 265-273, 2004.
[26] Y. Ku and C. B. Hsieh, "Photocatalytic decomposition of 2,4dichlorophenol in aqueous $\mathrm{TiO}_{2}$ suspensions," Water Research, vol. 26, no. 11, pp. 1451-1456, 1992. 

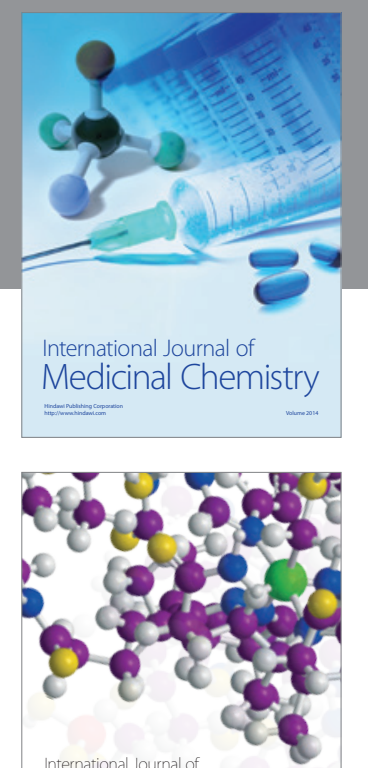

\section{Carbohydrate} Chemistry

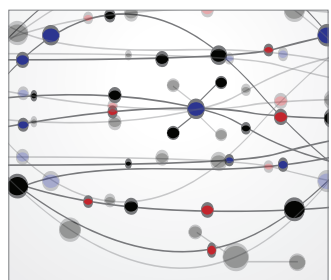

The Scientific World Journal
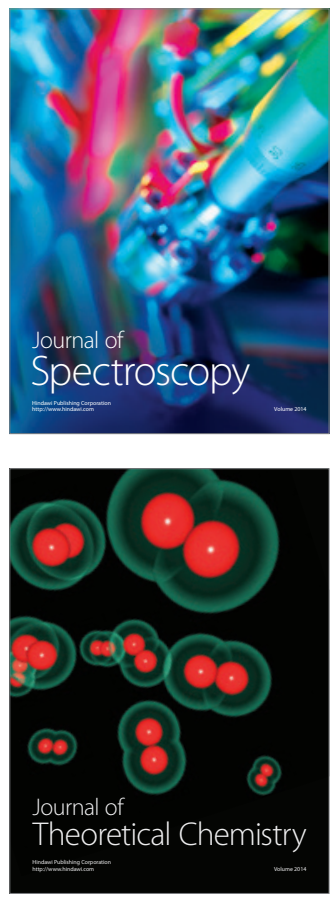
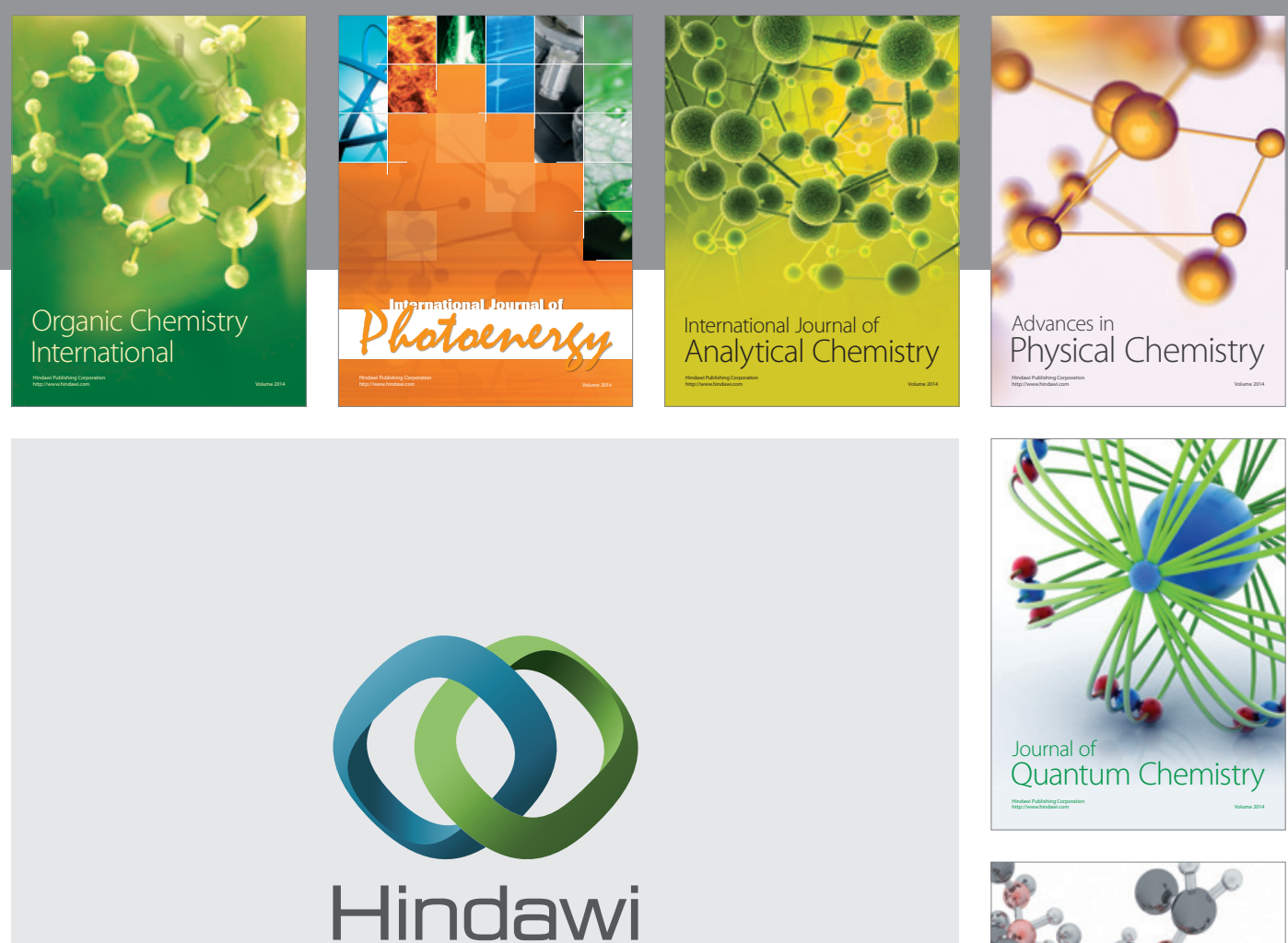

Submit your manuscripts at

http://www.hindawi.com

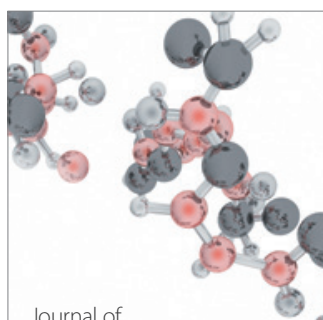

Analytical Methods

in Chemistry

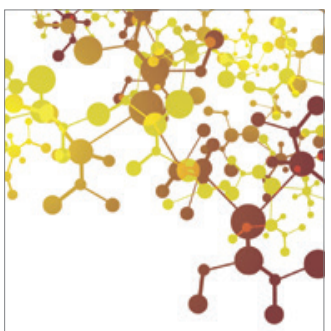

Journal of

Applied Chemistry

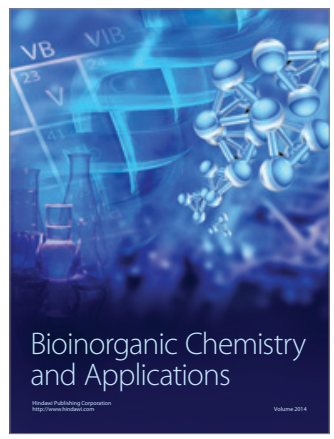

Inorganic Chemistry
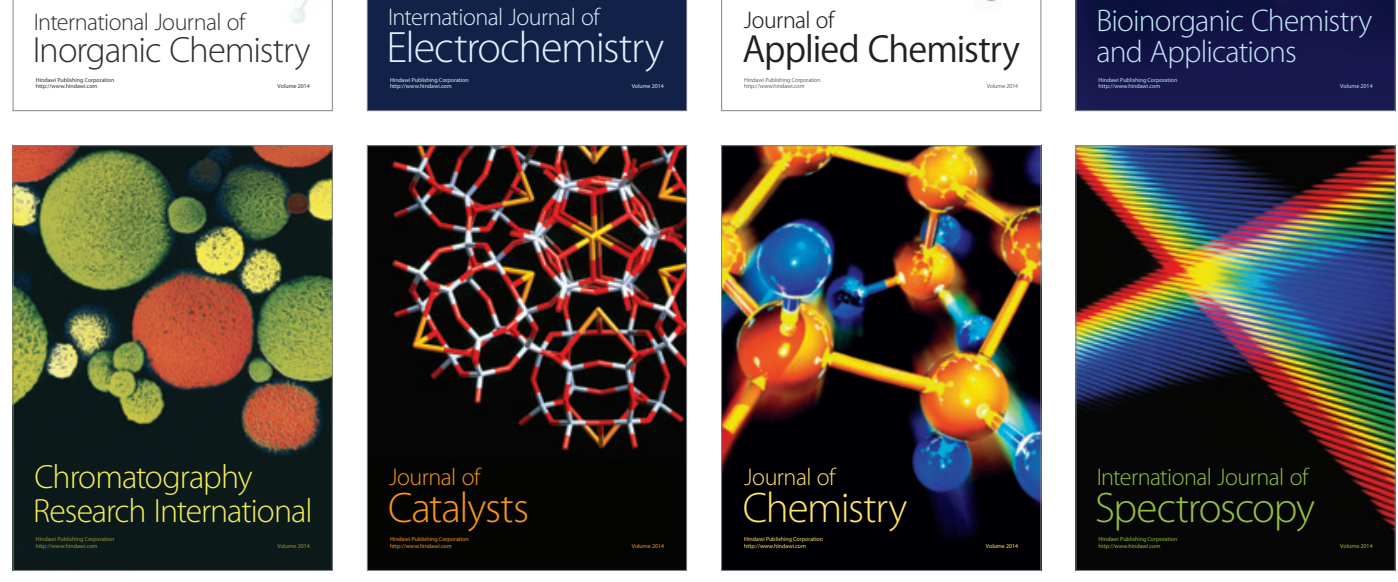